\title{
What is safety culture and risk-taking like at a large steel manufacturing company?
}

\author{
Hasse Nordlöf $f^{a}$ \\ ${ }^{a}$ Centre for Musculoskeletal Research, Department of Occupational and Public Health Sciences, Faculty of \\ Health and Occupational Studies, University of Gävle, 80176 Gävle, Sweden, haenof@hig.se
}

\begin{abstract}
Focus group interviews were conducted at a large steel manufacturing company with 1000 employees, in order to answer the research question: what is the safety culture and risk-taking like at the company, according to employees? Ten focus groups were used for data collection consisting of 6-8 employees each. The participants were operators from production. The interviews lasted $75 \mathrm{~min}$ and were digitally recorded and thereafter verbatim transcribed. Descriptive data was also collected from all participants by allowing them to fill out a short questionnaire. The results of this study will be presented at the conference as a poster presentation.
\end{abstract}

Keywords: BBS (Behavior based safety), Focus group discussion, OHS (Occupational health and safety), Implementation, Ergonomics

\section{Introduction}

Research within the fields of safety culture and safety climate has been around since the 1980's. The use of behavioral based safety (BBS) programs to improve safety within companies by focusing workplace culture, attitudes and behaviors, have existed since the 1970's and originates from North America. At the moment in Sweden, Europe, we notice an upswing of interest for workplace safety culture among companies. These are companies with dangerous work environments but that have already come a long way in improving their workplace safety and ergonomics standards by following the national legislations, using regular and systematic audits of the workplaces, using modern equipment and technology for safety, and with managements prioritizing the safety overall.

We collaborate with a large steel manufacturing company. The company aims to improve the safety culture within the organization, among workers and managers, by implementing different program activities. The company employs about 1000 people. The activities being implemented are: *Education in BBS for all employees. *Education in BBS for safety delegates. ${ }^{*}$ Training of risk observers. *Adoption of a BBS risk observational system with reports.
*Education of managers to act as role models in safety. *Improvements of different report systems. *Improvements in safety routines for contractors visiting the company industrial area. *Showing safety film for employees with discussion session afterwards. *Poster campaign with safety messages. *Improvements in the introduction routines for new employees. *And more.

The company focuses these activities not in order to get future payback in monetary terms, but actually to strive towards their company social responsibility (CSR) goal: that nobody should have to get injured on the job. In an upcoming study we intend to closely follow the implementation process of the company as a case study to be able to draw knowledge on how a company follows thru on the planned improvements. The present study is an initial exploration of the company and provides the basic understanding of the work environment setting where the company implements change. Research still needs to better understand different safety cultures.

\section{Research question}

What is the safety culture and risk-taking like at the company, according to employees? 


\section{Method}

The study design is a qualitative and descriptive study which aims to form inductive conclusions from the results. Focus group interviewing was the method of choice. Every focus group consisted of 6-8 participants. The participants were operators from production. We met 10 different focus groups for $75 \mathrm{~min}$ sessions. The participants were recruited from the company's five main mills to get a representative sample. In a systematic way, the operators were randomly asked to participate. The group discussion sessions were digitally recorded and thereafter verbatim transcribed. The main focus of the interviews was to chart what the safety culture and risk-taking is like at their workplaces. This was done by using three themes of discussion during the sessions: 1 . What do you think of the safety at your workplace? (Safety culture). 2. How is safety performed at your workplace? (Safety climate). 3. What can become better with the safety at you workplace? (Future perspective). To the three themes a couple of supportive questions were used to get the discussions going and also to get systematicity in the semi-structured interviews conducted.

During the interviews emphasis was put on followup questions, and asking the participants to explain more and to use own examples, in order to generate a useful and penetrating empirical material. The focus group sessions were conducted by a doctoral student. A research assistant also joined the sessions in order take notes, note body language, transcribe the material later, and to discuss the interviews and the material together with the doctoral student. Descriptive data was also collected from all participants by allowing them to fill out a short questionnaire. The questionnaire as well held six questions with Likert style answering alternatives. The questions aimed to be a quick capture of the participants' views on safety and a complement to the interview material.

\section{Results and discussion}

Results are right now being analyzed, but will be presented at the conference as a poster presentation. The aim is to describe the safety culture and risktaking of the employees at the large steel manufacturing company, and from the results form inductive conclusions. In the long run we will in further studies examine connections between company safety culture and ergonomics standards, and the risk for work related injuries. 